\title{
A arqueologia da psicodinâmica do trabalho no Brasil
}

\author{
Kátia Barbosa Macêdo e Roberto Heloani ${ }^{2}$ \\ Pontifícia Universidade Católica de Goiás (Goiânia, Goiás, Brasil), \\ Universidade Estadual de Campinas (Campinas, São Paulo, Brasil)
}

O objetivo do texto é apresentar dados que constituíram a arqueologia da Psicodinâmica do Trabalho no Brasil. Metodologia: foram realizadas 16 entrevistas individuais com Dejours e outros pesquisadores brasileiros que contribuíram para a introdução e disseminação dela no país e que adotam a abordagem em suas pesquisas. Para as entrevistas, considerou-se como critério o levantamento dos pesquisadores que estiveram no CNAM e os componentes do GT (Grupo de Trabalho em Psicodinâmica do Trabalho) da ANPEPP (Associação Nacional de Pós-graduação e Pesquisa no Brasil). Os resultados são apresentados considerando quatro aspectos: as raízes da Psicodinâmica do Trabalho no Brasil; a expansão da Psicodinâmica no Brasil; divergências e convergências entre contexto francês e brasileiro; e críticas e limitações em relação à Psicodinâmica do Trabalho. Seguem as considerações finais.

Palavras-chave: Psicodinâmica, Arqueologia, Trabalho.

The archeology of work psychodynamics in Brazil

The purpose of the text is to present data that constituted the archeology of work psychodynamics in Brazil. Methodology: individual interviews were conducted with Dejours and 16 Brazilian researchers who contributed to the introduction and dissemination of it in the country and researchers that currently use this regard in their researches. For the interviews, the survey had considered as a criteria the researchers that had been in the CNAM and the components of the GT (working group) on Psychodynamics of the work of Anpepp (National Association of Postgraduate and Research in Brazil). Results are presented considering four aspects: the roots of the Psychodynamics in Brazil; the expansion of the Psychodynamic in Brazil; divergences and convergences between the French and Brazilian context; and critics and limits concerning the Psychodynamics. Afterwards conclusions are presented.

Keywords: Psychodynamic, Archaeology, Work.

\section{A introdução da psicodinâmica do trabalho no Brasil}

E m decorrência do trabalho do Alain Wisner de divulgação de seus estudos no Brasil, desde a década de 1970 já havia brasileiros visitando e colaborando com pesquisas no laboratório do CNAM, coordenado à época por Alain Wisner. Assim, participavam das atividades do laboratório tanto pesquisadores orientados por ele quanto por colegas. Alguns foram contemporâneos de Dejours, participando de projetos, pesquisas, discussões e formação em ergonomia, como Laerte Idal.

O estudo das relações entre homem e trabalho e suas consequências para a saúde mental destaca o papel de uma corrente francesa de pensamento denominada Psicopatologia do Trabalho, que se construiu com base nas concepções e pesquisas desenvolvidas por Christophe Dejours (1992, 2004). Inicialmente, a abordagem tinha como objetivo o estudo das relações entre saúde mental e trabalho. A psicodinâmica do trabalho é multidisciplinar. Desde sua constituição, ela se pauta em diálogos com a ergonomia, psicanálise, sociologia do trabalho, psicopatologia, psicologia, medicina do trabalho, dentre outras. Segundo Dejours (2004, p. 21):

1 Graduada em Psicologia pela Pontifícia Universidade Católica de Goiás (UCG), especialização em Psicanálise pela UCG, mestre em Psicologia Aplicada a las organizaciones pela EAE de Barcelona, mestre em Educação pela Universidade Federal de Goiás, doutora em Psicologia Social pela Pontifícia Universidade Católica (PUC) de São Paulo, com pós-doutorado em Educação pela Unicamp/CNAM, professora titular da PUC-Goiás, Psicanalista formada pela International Psychoanalytic Association (IPA).

2 Graduado em Psicologia pela Fundação Getúlio Vargas, mestre e doutor em Psicologia pela PUC-São Paulo, professor livre docente da Unicamp e FGV São Paulo. 
Essa disciplina - inicialmente denominada psicopatologia do trabalho - tem por objeto e estudo clínico e teórico da patologia mental decorrente do trabalho. Fundada ao final da II Guerra por um grupo de médicos - pesquisadores liderados por L. Le Guillant, ela ganhou há uns 15 anos um novo impulso que a levou recentemente a adotar a denominação de "análise psicodinâmica nas situações de trabalho", ou simplesmente "psicodinâmica do trabalho". Nesta evolução da disciplina, a questão do sofrimento passou a ocupar uma posição central.

Segundo o autor, essa abordagem tem por objeto de pesquisa a vida psíquica no trabalho e, como foco, o sofrimento psíquico e as estratégias de enfrentamento utilizadas pelos trabalhadores para a superação e a transformação do trabalho em fonte de prazer.

Conhecer como ela chegou ao Brasil e como ocorreu sua expansão foi o ponto de partida para a pesquisa, que objetivou analisar como se constituiu a arqueologia da Psicodinâmica do Trabalho no Brasil e sua expansão. Aqui, o termo arqueologia possui dois significados, sendo o primeiro advindo de sua etimologia. A palavra "arqueologia" surgiu da junção de dois termos gregos: archaios, que significa "passado" ou "antigo" e logos, que quer dizer "ciência" ou "estudo"; assim sendo, arqueologia significa "ciência que estuda o passado" ou "ciência que estuda o antigo" (Michaelis, 2018, s.p.). Nesse sentido, foi necessário levantar dados documentais e realizar entrevistas com o objetivo de reconstituir essa história. O segundo significado se refere ao sentido de Foucault (1969), que utiliza o termo propondo um método que parte da história das ideias, penetra nas disciplinas existentes, as discute e as reinterpreta e, desse modo, busca definir os próprios discursos constituintes da disciplina estudada.

\section{Método}

Utilizou-se como técnicas para a coleta de dados a análise documental e a entrevista individual. Foram realizadas 16 entrevistas individuais, sendo uma com Dejours e outras 15 com pesquisadores brasileiros que contribuíram para sua introdução e disseminação no país, os quais adotam a abordagem em suas pesquisas e aceitaram participar da pesquisa. Para as entrevistas, considerou-se como critério o levantamento dos pesquisadores que estiveram no CNAM e foram indicados por Dejours em uma entrevista, sendo: Maria Irene Betiol; Laerte Idal Sznelwar; Heliete Karam; Álvaro Crespo Merlo; Selma Lancman; Kátia Tarouquella Brasil; Elisabeth Zulmira Rossi; Seiji Uchida; João de Deus Gomes da Silva; Paulo César Zambroni; Eduardo Rodrigues Peyon; e Juliana Barros Oliveira. Além desses participantes, também foram entrevistados alguns dos componentes do GT em Psicodinâmica do Trabalho da ANPEPP. Foram eles: Janine Kieling; Carla Vaz; Rosângela Dutra e Leda Gonçalves. Os dados foram analisados por meio da análise discursiva.

\section{Resultados}

Os resultados são apresentados utilizando fragmentos do discurso e trechos das entrevistas e foram organizados a partir de três categorias de análise:

- As raízes da Psicodinâmica do Trabalho no Brasil;

- Divergências e convergências entre contexto francês e brasileiro;

- Críticas e limitações em relação à Psicodinâmica do Trabalho.

Deve-se ressaltar que a inserção de trechos das entrevistas nos resultados é intencional, e visa apresentar depoimentos de pessoas que compuseram essa história. A escolha de trechos não é tarefa fácil 
e, ao final, os autores acabam por fazer recortes e privilegiar certos aspectos em detrimento de outros não menos importantes. Isso se deu em virtude da limitação de formatação para o formato de artigo.

\section{As raízes da Psicodinâmica do Trabalho no Brasil}

Talvez um dos fatores que mais contribuíram para o interesse e aceitação da abordagem tenha sido a sua visão ampliada, complexa e crítica das relações de trabalho e seu caráter emancipatório. Dentre os participantes entrevistados, alguns pesquisadores salientaram seu caráter multidisciplinar, outros a amplitude do conceito do trabalho e do trabalhar, bem como sua importância na constituição da identidade do trabalhador e o impacto em sua saúde. Para outros, o próprio método proposto, que privilegia o diálogo, e o caráter emancipatório das intervenções, que se constituem em fatores diferenciais para se compreender as relações entre trabalhador e organização do trabalho. Apresento alguns trechos de entrevistas visando elucidar tais percepções:

Maria Irene Betiol: O trabalho vivo é, conforme título de uma de suas publicações, a grande contribuição da psicodinâmica do trabalho. A subjetivação do mundo e a inteligência do corpo se destacam dentro da característica do trabalho vivo e são grandes contribuições da teoria e da pesquisa do Prof. Dejours. Lembrando que a Psicodinâmica do Trabalho não se ocupa da patologia do trabalho ou da doença no trabalho; seu foco é a saúde e a normalidade, não obstante a carga que o trabalho possa vir a ter sobre o trabalhador.

Álvaro Merlo: A PDT traz importante contribuição para a discussão sobre saúde mental e trabalho devido à ênfase não apenas no sofrimento, mas também na relação de prazer possível de ser estabelecida com o trabalho. Além disso, o fato de visar sempre à coletividade e à organização do trabalho mostra-se fundamental, em contraposto às tentativas de individualização e culpabilização do trabalhador pelo adoecimento no trabalho. Explica que o trabalho tem uma outra função além do trabalho. $\mathrm{O}$ trabalho constitui a identidade, ele transforma as pessoas. É original, nenhuma outra faz isso.

Heliete Karan: A centralidade estruturante do trabalho e do trabalhar, articulando as dimensões sociopolítica e intrapsíquica, como sempre valorizei. $O$ fato de ser transdisciplinar faz com que a Psicodinâmica do trabalho aporte uma possibilidade radical para o campo da saúde mental, beneficiando, ao mesmo tempo, o sujeito e a sociedade; mas suas contribuições implicam tal complexidade que ela transcende o campo da saúde e leva-nos a pensar a própria condição humana. Em linhas gerais, sua principal contribuição é articular o trabalho como produção (poiesis) e o trabalho psíquico em todas as suas variantes, na perspectiva freudiana retomada na práxis por Christophe Dejours.

Como pode se perceber pelos depoimentos, a proposta da abordagem psicodinâmica surgiu como uma possibilidade de preencher uma lacuna ao propor um espaço de discussão sobre as questões ligadas ao trabalho, saúde do trabalhador e sua mobilização subjetiva. Esses fatores contribuíram para que ela fosse gradativamente adotada em estudos e pesquisas tanto nas universidades quanto em instituições que se beneficiaram de projetos de intervenção.

Além dessas características da Psicodinâmica, cabe ressaltar o momento histórico que se vivia no Brasil no que se refere às discussões entre as relações de trabalho e seu impacto na saúde 
do trabalhador. Por esse motivo, no início, além das relações com as universidades, teve caráter fundamental o suporte dos sindicatos.

Quando questionado acerca dos primórdios da Psicodinâmica do Trabalho no Brasil, Dejours, em uma entrevista (Macêdo \& Heloani, 2017), relembra a primeira visita ao Brasil e os primeiros contatos com pesquisadores brasileiros, os quais tiveram uma importância fundamental para a introdução da Psicodinâmica no país. Ele afirma:

Em julho de 1984, houve um seminário franco-brasileiro em São Paulo com pesquisadores franceses que teve na organização Helena Hirata e Annie Thébaud. Foi um evento importante que recebeu 20 pesquisadores franceses para discutir diversos temas: ergonomia, economia, sociologia, psicologia, psicopatologia do trabalho, epidemiologia, toxicologia. Foi a primeira vez que fui ao Brasil. . . . lá conheci vários brasileiros que estiveram ou frequentavam o laboratório de Alain Wisner: Laerte Idal Sznelwar, Neire dos Santos. Pessoas que fizeram a intermediação e que foram muito importantes foram Helena Hirata e Leda Leal Ferreira. Em seguida a esse seminário, os brasileiros decidiram fazer a tradução do livro Travail, usure mental, que foi traduzido como A loucura do trabalho. Em função disso voltei ao Brasil três anos depois, 1997, para o lançamento do livro. Uma pessoa que teve um papel importante no lançamento do livro foi o João Guilherme Vargas Neto, líder sindicalista. A Editora Oboré, juntamente com os sindicalistas, organizaram algumas viagens pelo Brasil para fazer conferências para a divulgação. Houve muita movimentação em relação ao livro que representava uma marcha para discutir assuntos de interesse do sindicato e abordava a política. Naquela época o original era a abordagem da Psicopatologia do Trabalho. Demonstrava e discutia a importância do trabalho para a vida, a vida ordinária, a vida na cidade, a sociedade e a saúde mental. É certo que os ergonomistas brasileiros acolheram e deram as boas-vindas para a Psicodinâmica do Trabalho. Ela foi beneficiada por toda a ligação construída anteriormente por Alain Wisner. Essa é a pré-história. A Fundacentro também teve um papel importante.

Dentre as pessoas citadas, é importante agregar a esse texto um trecho da entrevista de Maria Irene Betiol, uma das pesquisadoras que teve papel fundamental na introdução da Psicodinâmica do Trabalho no Brasil. Em seu depoimento, que corrobora com os dados citados por Dejours, ela relata alguns fatos marcantes:

Meu contato com a Psicodinâmica do trabalho foi através do primeiro livro traduzido em português: A loucura do trabalho. Este livro foi adotado como livro texto no curso de Psicologia Aplicada na FGV em São Paulo. Posso dizer que acompanhei a evolução da Psicodinâmica através das diversas publicações que foram surgindo ao longo da evolução da disciplina, e nada melhor do que ter que ensinar para melhor compreender um determinado tema, não importa qual seja ele. Isso também aconteceu comigo em relação à Psicodinâmica do Trabalho. A disciplina por mim administrada, Psicologia do Trabalho, encontrou nesta abordagem elementos muito especiais para discussão sobre o adoecimento no trabalho. Discutir o tema, conforme propõe o Prof. Dejours, não foi sem muita resistência por parte dos alunos de administração de empresas. Por um lado, a crença na expertise dos administradores para resolver as questões da "organização do trabalho" e, por outro, o suporte na Psicanálise para entender o sofrimento das pessoas que trabalham geravam desconforto nos alunos. Tem-se que levar em conta que o primeiro livro do Prof. Dejours traduzido no Brasil era de 1987 e o foco era o trabalhador de chão de fábrica, exceto o capítulo sobre os pilotos de caça. A teoria que estava em construção à época não

3 A entrevista, publicada na íntegra, está disponível em https://bit.ly/2XiZyDD e serão realizados recortes de alguns fragmentos visando elucidar pontos importantes da constituição da arqueologia e atender à finalidade deste artigo. 
dava muitas perspectivas sobre a questão do prazer e saúde através do trabalho. Estes elementos necessitavam mais elaborações por parte do autor.

Nos anos 1990 criei na EAESP/FGV um Centro de Estudos e Pesquisa do Trabalho (CEPT) com alguns professores de Psicologia. O grupo discutia temas relacionados ao trabalho, além de receber vários pesquisadores externos à FGV. Na ocasião fui a Paris e pedi uma entrevista com o Prof. Dejours. Fui recebida com muita simpatia pelo Dejours que me disponibilizou vários artigos e textos que já tinham evoluído em relação à publicação do livro de 1987. Alguns desses textos foram discutidos dentro do CEPT e traduzidos por alguns professores do Centro. Obtive a autorização da publicação dos textos escolhidos pelos professores do CEPT e, em 1994, no primeiro dia das Conferências em São Paulo, o livro Psicodinâmica do Trabalho: contribuições da escola dejouriana à análise da relação prazer, sofrimento e trabalho, editado pela Atlas, foi lançado. O livro foi muito bem aceito pelos pesquisadores brasileiros e já atendia àquela inquietação minha e dos alunos de administração a respeito da lacuna sobre ser o trabalho um elemento criativo e não só adoecedor. Pela primeira vez um texto em português tratou a questão da Metodologia em Psicodinâmica do Trabalho. Alguns artigos deste livro sensibilizaram engenheiros ergonomistas mais até do que administradores. Este aspecto é interessante, pois permitiu uma pesquisa conjunta de duas professoras da EAESP, Profa. Maria José Tonelli e eu com professores engenheiros ergonomistas da UFSCar.

É importante ressaltar a significativa contribuição do professor Seiji Uchida que, como representante da segunda geração de professores da FGV-SP que trabalham com Psicologia, ajudou a consolidar a abordagem dejouriana nesta escola de administração, o que seguramente contribuiu para sua disseminação entre administradores nela formados. Ele também estabeleceu uma forte parceria com dois professores da USP: Selma Lancman, da Faculdade de Medicina, Departamento de Terapia Ocupacional, e Laerte Idal, do Departamento de Engenharia da Produção da Escola Politécnica. Esta parceria entre os pesquisadores e as instituições possibilitou a ancoragem da PDT no Brasil, principalmente na área da produção.

Dejours continua seu relado sobre a contribuição dos brasileiros para a divulgação da PDT no Brasil, comentando que:

Eu penso que, antes de falar da segunda etapa, houve a Maria Irene Betiol, professora da Fundação Getúlio Vargas, que teve um papel importante na tradução do livro. Havia vários encontros com pessoas lá, dentre elas Edith Seligmann-Silva, outra pessoa importante naquela época, Arakcy [Martins Rodrigues], socióloga 4 , e que era orientadora de tese do Seiji Uchida. Ela foi muito importante.

A professora Maria Irene Betiol também abordou essa etapa, comentando que:

Importa, agora, dizer que meu interesse sobre o tema se expandiu e, juntamente com a profa. Maria José Tonelli, traduzi outro livro do prof. Dejours, intitulado O fator humano, lançado em 1997 e editado pela Fundação Getúlio Vargas. Em 1999 foi lançado o livro Conferências Brasileiras: identidade, reconhecimento e transgressão no trabalho (edição GV/Fundap). Esse livro apresenta as quatro conferências ocorridas em São Paulo em 1994, além de um capítulo específico sobre a questão da demanda em Psicodinâmica do Trabalho. Em 2004, foi lançado o livro A Ergonomia em busca de seus princípios: debates epistemológicos, cuja tradução coordenei e foi editado pela Blücher, edição FGV/ EAESP/Ufscar. Nesse livro, um artigo de Dejours discorre sobre Epistemologia e Ergonomia.

4 É importante comentar que a professora Arakcy tinha formação em filosofia, e posteriormente em psicologia na abordagem psicanalítica, e não em sociologia como Dejours afirmou. 
Como resultado do trabalho de Alain Wisner junto ao Laboratório do CNAM, houve um forte intercâmbio entre pesquisadores de lá com outros países, dentre eles o Brasil. Esse intercâmbio teve papel importante na disseminação das pesquisas e abordagens desenvolvidas pelo laboratório. Ao ser perguntado sobre os pesquisadores brasileiros envolvidos com o Laboratório do CNAM desde o início, Dejours nomeia alguns que participaram de atividades e contribuíram de forma significativa para a divulgação e expansão da PDT no Brasil. Segundo ele:

Uma pessoa que teve um importante papel na divulgação da Psicopatologia do Trabalho foi Irene Hirata e foi fundamental, pois ela tinha ligações entre a França e o Brasil e divulgou a Psicodinâmica do Trabalho entre os sociólogos brasileiros. Por intermédio dos ergonomistas e dos sociólogos, houve também uma divulgação entre os engenheiros, que tiveram um interesse para a tradução do livro O fator humano. Os engenheiros ficaram interessados também pela PDT. Na medicina do trabalho também. Em 1997, quando fui para uma conferência em Brasília, me encontrei com Julia Abrahão. Ela estudou ergonomia na França por muitos anos. . . . depois disso, há outras pessoas que tiveram um papel importante: Laerte Idal; Heliete Karam; Selma Lancman; Ana Magnólia Mendes; Álvaro Merlo; Elisabeth Rossi, Seiji Uchida; Francilene Macêdo; Juliana Barros, Maria Amélia; Katia Brasil; Leda Ferreira; Maria Bernadete Macêdo.

A partir das indicações de Dejours acerca dos pesquisadores brasileiros que frequentaram o laboratório desde 1974, foi elaborada a Tabela 1, que apresenta uma relação dos pesquisadores brasileiros que visitaram ou realizaram atividades no CNAM no período de 1974 a 2016. É importante ressaltar que este texto não teve como objetivo esgotar todos os pesquisadores, e sim trabalhar com os citados pelo próprio Dejours na entrevista supracitada.

Como pode ser observado, dos 20 pesquisadores listados, 13 participaram do presente estudo. Chama a atenção o tipo de vínculo, pois, além dos orientandos de mestrado e doutorado, o laboratório do CNAM recebe vários pesquisadores provenientes de outros países para fazer pós-doutorado ou mesmo fazer uma parte de seu doutorado no grupo de pesquisa, no Brasil denominado de "bolsa sanduíche". Além disso, também chama a atenção o fato da diversidade de formação dos pesquisadores, o que evidencia seu caráter multidisciplinar e a abertura do laboratório para internacionalização.

Ao ser perguntado acerca de suas relações com pesquisadores no Brasil, Dejours comenta:

O primeiro é o grupo da USP, que conta com a Selma Lancman, Laerte Idal e Seiji Uchida, desenvolvem várias pesquisas utilizando a Psicodinâmica do Trabalho. Em Brasília, atualmente o grupo da Católica de Brasília, com Katia Brasil. Outro grupo importante atualmente para mim é o que desenvolve pesquisa na magistratura brasileira com Leonardo Wandeli, que é juiz e desenvolve um trabalho importante na área do Direito. Tenho outras relações com pesquisadores no Brasil, alguns ligados à Psicanálise e Psicossomática. Em Belo Horizonte, Maria Tereza Carvalho Ribeiro, que trabalha com seu marido, Paulo Carvalho em Psicanálise e Psicossomática no Trabalho. No Rio de Janeiro, Marta Rezende Cardoso. Em Porto Alegre, um psicanalista que se chama José Carlos Calich. Em João Pessoa, alguns psicanalistas ligados à Fundação Jean Laplanche, onde eu sou um dos diretores. Em São Paulo, Sedes Sapientiae, há um grupo de trabalho nesse instituto, dirigido por Mario Fucks. Há uma formação de Psicodinâmica do Trabalho lá. Em Goiás, na PUC-Goiás, Kátia Barbosa Macêdo, que utiliza a Psicodinâmica do Trabalho nas pesquisas e desenvolve parcerias junto ao MPT e ao TRT em Goiás. 
Tabela 1. Levantamento de Brasileiros no CNAM e/ou Université de Paris relacionados à PDT, citados por Dejours, apresentados em ordem cronológica, elaborados pelos autores a partir de registro no CNAM e Currículo Lattes dos pesquisadores em março de 2017

\begin{tabular}{|c|c|c|}
\hline Ano & Nome e formação & Tipo de vínculo \\
\hline $\begin{array}{l}1974 \\
\text { Entrevistada }\end{array}$ & $\begin{array}{c}\text { Maria Irene Betiol } \\
\text { Graduação, mestrado e doutorado em Psicologia }\end{array}$ & Visitante \\
\hline 1979 & Helena Sumiko Hirata & $\begin{array}{l}\text { Doutorado Paris 5, Livre docência } \\
\text { Université de Versailles em } 1997\end{array}$ \\
\hline 1986 & Júlia Issy Abrahão & $\begin{array}{l}\text { Doutorado em Ergonomia, orientada } \\
\text { pelo Alain Wisner }\end{array}$ \\
\hline $\begin{array}{l}1992 \\
\text { Entrevistado }\end{array}$ & $\begin{array}{c}\text { Laerte Idal Sznelwar } \\
\text { Graduação em Medicina, mestrado e doutorado em Ergonomia. } \\
\text { Pós-doutorado no CNAM }\end{array}$ & $\begin{array}{l}\text { Doutorado em ergonomia CNAM, } \\
\text { orientado pelo Alain Wisner }\end{array}$ \\
\hline 1993 & Maria Bernadete Ferreira Macedo & $\begin{array}{l}\text { Doutorado em sociologia do Trabalho, } \\
\text { Paris 5, orientada pela Danièle Kergoat }\end{array}$ \\
\hline $\begin{array}{l}1994 \\
\text { Entrevistada }\end{array}$ & $\begin{array}{c}\text { Heliete Karam } \\
\text { Graduação em Serviço Social, mestrado em Psicologia, doutorado } \\
\text { em Psicologia no CNAM }\end{array}$ & $\begin{array}{c}\text { Doutorado CNAM, orientada pelo } \\
\text { Dejours }\end{array}$ \\
\hline $\begin{array}{l}1996 \\
\text { Entrevistado }\end{array}$ & $\begin{array}{c}\text { Álvaro Crespo Merlo } \\
\text { Graduação em Medicina, mestrado em Medicina da Saúde e } \\
\text { doutorado em Sociologia, pós doutorado na França e na Bélgica }\end{array}$ & $\begin{array}{l}\text { Doutorado em Sociologia Paris } 5 \text {, } \\
\text { orientado pelo Benjamin Coriat }\end{array}$ \\
\hline $\begin{array}{l}2000 \\
\text { Entrevistada }\end{array}$ & $\begin{array}{l}\text { Selma Lancman } \\
\text { Graduação em Terapia Ocupacional, mestrado em Saúde Coletiva } \\
\text { e doutorado em Saúde Mental. Pós-doutorado em Psicologia no } \\
\text { CNAM com Dejours }\end{array}$ & $\begin{array}{c}\text { Pós-doutorado CNAM, orientada pelo } \\
\text { Dejours }\end{array}$ \\
\hline $\begin{array}{l}2004 \\
\text { Entrevistada }\end{array}$ & $\begin{array}{c}\text { Kátia Tarouquella Brasil } \\
\text { Graduação, mestrado em doutorado em Psicologia. Fez sanduíche } \\
\text { no CNAM }\end{array}$ & $\begin{array}{l}\text { Doutorado sanduíche no CNAM, } \\
\text { orientada pelo Dejours no sanduíche } \\
\text { com Francisco Martins }\end{array}$ \\
\hline 2006 & Ana Magnólia Mendes & $\begin{array}{c}\text { Pós-doutorado CNAM, orientada pelo } \\
\text { Dejours }\end{array}$ \\
\hline $\begin{array}{l}2007 \\
\text { Entrevistada }\end{array}$ & $\begin{array}{l}\text { Elizabeth Zulmira Rossi } \\
\text { Graduação em Pedagogia, mestrado e doutorado em Psicologia, } \\
\text { sanduíche no CNAM com Dejours }\end{array}$ & $\begin{array}{l}\text { Sanduíche Doutorado UnB com Ana } \\
\text { Mendes, e no CNAM pelo Dejours }\end{array}$ \\
\hline $\begin{array}{l}2009 \\
\text { Entrevistado }\end{array}$ & $\begin{array}{c}\text { Seiji Uchida } \\
\text { Graduação, mestrado e doutorado em Psicologia. Pós-doutorado } \\
\text { no CNAM com Dejours }\end{array}$ & $\begin{array}{c}\text { Pós-doutorado CNAM, orientado pelo } \\
\text { Dejours }\end{array}$ \\
\hline $\begin{array}{l}2012 \\
\text { Entrevistado }\end{array}$ & $\begin{array}{c}\text { João de Deus } \\
\text { Graduação em Psicologia, mestrado em Saúde Mental, doutorado } \\
\text { em Psicologia orientado pelo Dejours }\end{array}$ & Doutorado orientado pelo Dejours \\
\hline 2013 & Francilene Maria Melo e Silva & $\begin{array}{c}\text { Doutorado em Psicologia CNAM, } \\
\text { orientada pelo Dejours }\end{array}$ \\
\hline $\begin{array}{l}2014 \\
\text { Entrevistada }\end{array}$ & $\begin{array}{l}\text { Rosângela Dutra } \\
\text { Graduação em Psicologia, mestrado em Educação, doutorado em } \\
\text { Desenvolvimento Sustentável. Pós-doutorado no CNAM }\end{array}$ & $\begin{array}{l}\text { Participa do GT de Psicodinâmica do } \\
\text { Trabalho da Anpepp no Brasil }\end{array}$ \\
\hline 2014 & Maria Amélia Dias & $\begin{array}{l}\text { Sanduíche do Doutorado UFG, no } \\
\text { CNAM orientada pelo Dejours }\end{array}$ \\
\hline $\begin{array}{l}2016 \\
\text { Entrevistado }\end{array}$ & $\begin{array}{c}\text { Paulo César Zambroni } \\
\text { Graduação em Psicologia, mestrado em Ergonomia e doutor em } \\
\text { Psicologia }\end{array}$ & $\begin{array}{c}\text { Pós-doutorado CNAM, orientado pelo } \\
\text { Dejours }\end{array}$ \\
\hline $\begin{array}{l}2016 \\
\text { Entrevistado }\end{array}$ & $\begin{array}{c}\text { Eduardo Rodrigues Peyon } \\
\text { Graduação e mestrado em Psicologia, cursando doutorado em } \\
\text { Psicologia, fazendo sanduíche no CNAM }\end{array}$ & $\begin{array}{l}\text { Sanduíche doutorado Universidade } \\
\text { Veiga de Almeida, no CNAM } \\
\text { orientado pelo Dejours }\end{array}$ \\
\hline 2016 & Kátia Barbosa Macêdo & $\begin{array}{c}\text { Pós-doutorado Unicamp, orientada } \\
\text { por Roberto Heloani e visitante } \\
\text { orientada pelo Dejours }\end{array}$ \\
\hline $\begin{array}{l}2016 \\
\text { Entrevistada }\end{array}$ & $\begin{array}{c}\text { Juliana Barros Oliveira } \\
\text { Graduação, mestrado e doutorado em Psicologia }\end{array}$ & $\begin{array}{l}\text { Doutorado na USP com Selma } \\
\text { Lancman e no CNAM orientada pelo } \\
\text { Dejours no sanduíche }\end{array}$ \\
\hline
\end{tabular}




\section{A expansão da psicodinâmica do trabalho no Brasil}

A via de inserção prioritária da Psicodinâmica do Trabalho no Brasil ocorreu pelas Universidades (FGV-SP, em 1984), além dos sindicatos. E sua expansão também se deve a esse tipo de inserção nas universidades. Em diversas regiões do Brasil, em universidade públicas, privadas ou confessionais, os pesquisadores que utilizam a PDT o fazem preferencialmente dentro do âmbito de ensino, pesquisa e extensão. Há registro de intervenções realizadas fora da universidade, porém com pesquisadores ligados a elas.

Das várias ciências que utilizam a PDT no Brasil, a que mais se destaca é a Psicologia. No Brasil, há a Associação Nacional de Pesquisa e Pós-graduação em Psicologia (ANPEPP), que é uma organização sem fins lucrativos e apartidária fundada em 1983, que tem por objetivo congregar programas de pós-graduação vinculados a instituições de ensino superior para fomentar e estimular a formação de profissionais para pesquisa e pós-graduação em Psicologia. Realiza bienalmente um simpósio, cujo principal objetivo é discutir a pesquisa, a política e a formação no âmbito da pósgraduação em Psicologia no Brasil. Dos vários grupos de trabalho ou GTs, há um que foi proposto em 2012. Em decorrência dos pesquisadores brasileiros adotarem a Psicodinâmica do Trabalho no campo da produção científica, foram defendidas várias dissertações de mestrado e teses de doutoramento dentro da abordagem da PDT a partir de 2001. À medida que os grupos de estudos se expandiam, a partir de 2007, surgiram os laboratórios de pesquisa específicos da abordagem, associados às universidades em todas as regiões brasileiras e no Distrito Federal.

No Brasil, a divulgação dos resultados das pesquisas e intervenções é feita em duas frentes de trabalho: pela realização de eventos científicos e pela publicação de livros e artigos em periódicos, sendo os dois últimos os mais comuns. A tendência dos pesquisadores de concentrar suas publicações em periódicos visa atender a critérios estabelecidos pelas agências de fomento e avaliadoras dos cursos de pós-graduação.

A Psicodinâmica do Trabalho é uma abordagem bem aceita por pesquisadores brasileiros, sendo o Brasil, juntamente com o Canadá, os países onde ela floresceu, além da França, conforme dados levantados em pesquisa recente realizada por Machado \& Macêdo (2016). No que se refere aos eventos, deve-se ressaltar que desde que a Psicodinâmica foi adotada por pesquisadores brasileiros, os resultados de suas pesquisas foram apresentados em diversos eventos em várias áreas afins. No entanto, a partir de 2007, começou a haver congressos específicos para a temática. Conforme Machado e Macêdo (2016), em 2007 foi realizado o I Simpósio Brasileiro de Psicodinâmica do Trabalho, que reuniu, em Brasília, pesquisadores e especialistas na área e que contou com a participação de Christophe Dejours durante todo o evento. Esse evento teve tão boa repercussão que outras edições foram realizadas visando divulgar a PDT e possibilitar a formação de redes de pesquisa no Brasil.

Tabela 2. Eventos de psicodinâmica realizados no Brasil no período entre 2007 a 2015

\begin{tabular}{|c|l|}
\hline Ano & \multicolumn{1}{|c|}{ Evento } \\
\hline 2007 & I Simpósio Brasileiro de Psicodinâmica do Trabalho, em Brasília, com a participação de Christophe Dejours durante todo evento. \\
\hline 2009 & $\begin{array}{l}\text { O I Congresso Brasileiro de Psicodinâmica do Trabalho e Clínica do Trabalho e II Simpósio Brasileiro de Psicodinâmica do } \\
\text { Trabalho foi realizado em Brasília, promovido pela UnB e o GT de Psicodinâmica e clínica do trabalho da Anpepp. }\end{array}$ \\
\hline 2010 & $\begin{array}{l}\text { I Congresso da Associação Internacional de Psicodinâmica e Psicopatologia do Trabalho e o VI Colóquio Internacional de } \\
\text { Psicodinâmica e Psicopatologia do Trabalho e foi realizado em São Paulo com a promoção da referida Associação e da USP. }\end{array}$ \\
\hline 2011 & $\begin{array}{l}\text { O II Congresso Brasileiro de Psicodinâmica do Trabalho e Clínica do Trabalho e III Simpósio Brasileiro de Psicodinâmica } \\
\text { do Trabalho foi realizado em Brasília, promovido pela UnB e o GT de Psicodinâmica e Clínica do Trabalho da Anpepp. }\end{array}$ \\
\hline 2013 & $\begin{array}{l}\text { O III Congresso Brasileiro de Psicodinâmica do Trabalho e Clínica do Trabalho e IV Simpósio Brasileiro de Psicodinâmica do } \\
\text { Trabalho foi realizado em Gramado-RS, promovido pela UnB e o GT de Psicodinâmica e Clínica do Trabalho da Anpepp. }\end{array}$ \\
\hline 2015 & $\begin{array}{l}\text { O IV Congresso Brasileiro de Psicodinâmica do Trabalho e Clínica do Trabalho e V Simpósio Brasileiro de Psicodinâmica do } \\
\text { Trabalho foi realizado em Manaus-AM, promovido pela UnB e o GT de Psicodinâmica e Clínica do Trabalho da Anpepp. }\end{array}$ \\
\hline
\end{tabular}


O número de participantes dos referidos eventos, bem como o número de trabalhos apresentados nos mesmos indicam uma expansão da Psicodinâmica do Trabalho, com crescimento do número de pesquisadores e um maior interesse por essa abordagem no Brasil. Deve ser ressaltado ainda que vários trabalhos apresentados não estavam ligados diretamente a universidades, mas eram provenientes diretamente de intervenções realizadas em outros âmbitos institucionais, por exemplo a Fundação Oswaldo Cruz (Fiocruz), Petrobrás, dentre outras. Cabe uma ressalva em relação aos eventos. No início, os grupos de pesquisa de São Paulo e Brasília trabalhavam integrados; porém, a partir de divergências metodológicas houve um distanciamento, o que teve como consequência a proposta de eventos realizados de forma independente, inclusive em relação à própria participação do Dejours e de outros pesquisadores ligados ao CNAM.

A outra forma já mencionada de divulgação e expansão da PDT é por meio de publicações. Machado \& Macêdo (2016) realizaram estudos que tiveram como objetivo levantar o panorama das pesquisas em PDT publicadas no Portal de Periódicos da Coordenação de Aperfeiçoamento de Pessoal de Nível Superior (Capes)/Ministério da Educação (MEC) ${ }^{5}$ no período entre 2004 e 2014. Esse portal foi escolhido pelo fato de ser uma biblioteca virtual que disponibiliza às instituições de ensino e pesquisa do Brasil a melhor produção científica internacional, tendo em seu acervo mais de 36 mil títulos com textos completos, 130 bases referenciais. Foram identificados 95 artigos nacionais publicados em português e 50 artigos internacionais escritos em francês e inglês por 179 autores, o que indica a importância da abordagem no Brasil. Ao analisar as redes de cooperação científica entre instituições e suas respectivas regiões geográficas, percebe-se que a região geográfica no Brasil com maior número de cooperações é a região sudeste, destacando-se a Fiocruz, a Universidade de São Paulo (USP), Universidade Federal Fluminense (UFF), Universidade Federal do Rio de Janeiro (UFRJ) e Universidade do Estado do Rio de Janeiro (UERJ). Todos esses dados indicam a importância crescente que essa abordagem teve nas pesquisas brasileiras.

\section{Divergências e convergências entre o contexto francês e brasileiro}

O próprio conceito de trabalho para Dejours $(1992,1999,2008,2009)$ ressalta a importância de considerar as diferenças entre o trabalho prescrito e o real. A prescrição se impõe ao trabalhador e se traduz no planejamento, nos objetivos das tarefas, na definição de regras comportamentais, no estabelecimento de normas e nos procedimentos técnicos, nos estilos de gerenciamento, nas pressões e nos regulamentos do modo operatório. $\mathrm{O}$ real do trabalho representa aquilo que, na experiência do trabalho, se dá a conhecer ao sujeito por sua resistência ao domínio, ao savoir faire, à competência, ao conhecimento e até à ciência. A experiência do real no trabalho se traduz pelo confronto com o fracasso.

A constatação da defasagem entre o trabalho prescrito e o real fez com que Dejours defina o trabalho como atividade coordenada de homens e mulheres para fazer face ao que não pode ser obtido pelo estrito cumprimento das prescrições, ou seja, ao que deve ser "ajustado, rearranjado, imaginado, inventado, acrescentado pelos homens e pelas mulheres para levar em conta o real do trabalho" (Dejours, 2005, p. 43). Caso não haja espaço para a inovação do trabalhador, sem o engajamento do corpo, da inteligência humana e da cooperação, a execução mecânica limitada das prescrições pode levar ao que é conhecido como greve de zelo ou operação padrão e que corresponde a um ato de bloqueio da produção. Esse ato possui caráter político e tem o objetivo de mostrar a ineficácia das prescrições, ao mesmo tempo que visa ao reconhecimento da importância do engajamento do trabalhador para o desenvolvimento de suas atividades.

5 Portal de Periódicos CAPES/MEC - O Portal de Periódicos foi oficialmente lançado em 11 de novembro de 2000, na mesma época em que começavam a ser criadas as bibliotecas virtuais e quando as editoras iniciavam o processo de digitalização dos seus acervos (CAPES, 2017). 
O método proposto por essa abordagem é pré-requisito para sua utilização e parte do princípio de que na Psicodinâmica do Trabalho deve haver um envolvimento do pesquisador com o grupo de trabalhadores e que a construção de conhecimento acerca da relação entre trabalhador e organização do trabalho, necessariamente, deve ser coletiva. Nesse sentido, é sempre uma pesquisa-ação. $O$ método preconizado pela Psicodinâmica do Trabalho é construído a partir de uma série de etapas que servem de norteadores para o trabalho de campo. As etapas previstas nesse método são: constituição da demanda; pré-pesquisa; pesquisa propriamente dita; validação; e elaboração de relatório. Essas etapas são fundamentais para o alcance dos objetivos propostos. Deve compreender que cada pesquisa possui situações de trabalho peculiares ou específicas e poderá exigir dos pesquisadores algumas adaptações que, no entanto, não devem comprometer a integridade do método. Dejours (2017), na entrevista supracitada, afirma que:

Do ponto de vista do método, o mais importante é a possibilidade de fazer reuniões com o coletivo, montar grupos de trabalho com trabalhadores de empresas. Com trabalhadores de ministérios ou de administrações, pouco importa se forem públicas ou privadas. Conseguir montar um grupo de trabalhadores voluntários para refletirem sobre a questão das relações entre eles e a partir das perguntas sobre as dificuldades encontradas por eles no exercício do trabalho e voltar a questão da subjetividade e da organização do trabalho. O mais importante é a reunião do trabalho à medida que permite apreender coisas sobre o trabalho, coisas que poderiam ser levantadas pelas entrevistas individuais. É porque no interior dessa discussão coletiva não há apenas uma discussão entre os trabalhadores e os pesquisadores, mas também uma discussão que começa entre os membros do grupo de trabalho. É o que faz o objeto da discussão entre eles, são sempre as questões evidentemente muito significativas, em vista dos problemas que elas ocupam. Envolvem o sofrimento no trabalho, o prazer no trabalho e, sobretudo, o que é importante nesse grupo de trabalho é que não se trata somente de um trabalho de investigação.

Apesar dos dados acima apontarem para uma expansão da abordagem no Brasil, ela nem sempre foi utilizada de forma Stricto sensu, ou seja, nem todos os pesquisadores a utilizaram da forma prescrita pelo método. Houve adaptações, ampliações e, conforme relato do próprio Dejours: "Alguns pesquisadores vieram ao CNAM e realizaram atividades comigo, voltaram ao Brasil e realizaram eventos, publicaram coletâneas das quais participei no início. Depois, realizaram alianças estratégicas por questões de política, fizeram uma miscelânea e um sincretismo."

Ao serem perguntados de que modo utilizam a Psicodinâmica do Trabalho, os entrevistados indicaram algumas possibilidades. Alguns adotam a abordagem de forma exclusiva, outros fazem interlocuções dela com outras disciplinas como Ergonomia, Psicanálise, Psicossomática, Sociologia, dentre outras.

Laerte Sznelwar: Sou médico e ergonomista, mas em algumas pesquisas utilizo a PDT. Eu nunca saio da Ergonomia, já fiz vários trabalhos em Psicodinâmica com Selma, Seiji, Vandelli. Iniciamos abordando o tema "Sujeito e trabalho", fazendo um diálogo entre a Ergonomia e a Psicodinâmica. Minha tese de livre docência abordou o protagonismo do sujeito e do trabalhador. O protagonismo do trabalho na produção.

Álvaro Merlo: Eu e Ana Magnólia começamos a analisar a produção brasileira em PDT e vimos que muita coisa era feita usando apenas as categorias teóricas, mas não a metodologia prescrita do Dejours. A partir de 1987 criei uma disciplina Saúde do Trabalhador, já na Universidade como professor no curso de Medicina. Em 1988, criei o Ambulatório em Saúde do Trabalho e também o Centro de Pesquisa em Formação e Saúde do Trabalho. A Psicodinâmica faz parte da minha vida, apesar de não ser professor da Psicologia, e sim da Medicina. A PDT não ocupa a maior parte do meu tempo. 
Em relação ao método, alguns pesquisadores o adotam de forma Stricto Sensu, ou seja, não conseguem visualizar uma divisão entre as categorias teóricas e o método prescrito, até em função de sua epistemologia. Já outros pesquisadores adotam suas categorias teóricas e indicadores; porém, fazem adaptações em relação ao método prescrito por Dejours. Outro aspecto importante é o fato de o pesquisador estar inserido em um grupo de pesquisa, ou seja, ter outros colegas capacitados para realizar o método prescrito de forma estrita.

Seiji Uchida: Fui o pioneiro em defender uma tese de doutorado em Psicopatologia e Psicodinâmica do Trabalho. Não era ainda o método stricto sensu. Passei a trabalhar com Laerte após 1997 e, então, comecei a fazer o espaço de discussão coletivo. Desde 1994 tenho acompanhado os trabalhos de Dejours e a parceria com Laerte abriu outra possibilidade de compreender as relações de trabalho e realizar inúmeras pesquisas e intervenções.

Janine Kieling: PDT tem norteado muitas práticas e pesquisas que já desenvolvi e ainda desenvolvo. Primeiramente, me guiou nas práticas de intervenções na saúde mental de trabalhadores em situação de desemprego e de bombeiros, trabalhadores em situação de desemprego, aposentados, gestores, bombeiros, professores, trabalhadores rurais, agentes penitenciários, trabalhadores da saúde (hospitais, CAPS e UBS) e servidores públicos.

Uma observação importante é no que se refere à realização de pesquisas e seus fins. Se a pesquisa é realizada no âmbito de formação profissional na pós-graduação, tendo como um dos seus fins a elaboração de teses e dissertações, muitas exigências decorrem disso, inclusive em relação à pressão do tempo para defesa, exigências institucionais e das bancas. Quando a pesquisa ou intervenção tem um caráter de atender a demandas espontâneas, a realidade é outra.

Heliete Karam: Trabalho com a PDT desde 1998, com um trabalho inicialmente pela PUCRS junto à Prefeitura Municipal de Alvorada (RS), depois como autônoma, pois houve um desdobramento do projeto. Em Psicodinâmica do Trabalho, na forma como tenho trabalhado, considero que, além de contribuir para criar uma cultura na área (conforme acordado com Christophe Dejours em 1991), o resultado é o próprio processo e a construção e consolidação do espaço de discussão em organizações públicas.

Carla Vaz: Tenho realizado estudos pautados na Psicodinâmica do Trabalho. Nas orientações de alunos, seja na graduação ou nos pós, a Psicodinâmica está sempre presente. Desenvolvo, mais especificamente, desde 2008, pesquisas sobre o trabalho docente na educação superior pautadas na abordagem da Psicodinâmica do Trabalho.

Considerando que há diferenças culturais entre Brasil e a França, alguns pesquisadores realizam adaptações em relação ao uso da abordagem no contexto brasileiro. Alguns consideram que não há divergência, como pontua o relato de Heliete Karam, que ilustra esse entendimento. Heliete Karam comenta que, apesar das diferenças do contexto entre os dois países, os princípios de Dejours são universais: "Creio que não se trata de fazer ajustes, mas de levar em conta tais diferenças quando escutamos e acolhemos a palavra no coletivo, quando elaboramos as diagnoses etc. Os princípios sistematizados por Christophe Dejours são universais".

Janine Kieling: Não acho que a PDT seja uma teoria somente da França. Acredito que ela já existe em vários países. E acho que temos que desassociar a redução da PDT somente à França. Existem grandes diferenças culturais entre Brasil e França. E, por isso, temos que avançar na PDT no Brasil. Entre as principais adaptações estão a escuta individual e a redução do número de encontro com 
o grupo de trabalhadores (para um, dois ou três encontros). Outro delas seria a demanda vir do pesquisador e não do grupo. E, ainda, a utilização de escalas de medidas objetivas, junto com a escuta individual ou coletiva. Acredito que temos que adaptar a PDT pensada por ele à nossa realidade e desenvolver a PDT no Brasil e em outros países.

Outros pesquisadores sinalizam a necessidade de se fazer adaptações exatamente em função das diferenças. E essas adaptações vão desde formas alternativas de constituir a demanda; realizar somente entrevistas individuais em detrimento do espaço de discussão coletivo; diminuir o número de sessões e de participantes visando adaptar à realidade do campo pesquisado. Fragmentos de algumas entrevistas são apresentados visando ilustrar essas adaptações.

Seiji Uchida: Aqui no Brasil há muita dificuldade em relação à demanda, também das organizações aceitarem a realização de entrevistas coletivas. Aqui não há muito rigor no método. Como parecerista vejo muita adaptação incorreta. Dejours tem razão quando ele defende o seu campo e é o maior interessado nisso para que seja mantido o rigor e evitar deturpações.

Elisabeth Rossi: De certa forma, uma adaptação diz respeito à formulação da demanda. Na França, a demanda pela pesquisa-ação, via de regra, parte dos trabalhadores, dos sindicatos e, até mesmo, pela alta direção. Aqui no Brasil, como as empresas e nem mesmo os órgãos representativos dos trabalhadores possuem a mesma cultura, ocorre uma reconfiguração/construção da demanda pela pesquisa-ação em Psicodinâmica do Trabalho por parte dos pesquisadores das instituições de ensino superior.

Rosângela Dutra: Em alguns casos é possível fazer a aplicação do método de forma canônica. Em outros, realizo adaptações. As mais frequentes são coconstrução da demanda, que parte do pesquisador e não estava explicitada, pelo coletivo de trabalhadores, até que se oferecesse a possibilidade da realização da pesquisa com a metodologia dejouriana. A outra adaptação frequente é inserção de psicólogos que já atuam na organização de trabalho na equipe de pesquisadores.

Leda Gonçalves: Sim, principalmente trazendo mais o mundo do sujeito. Você vai com um roteiro, mas é o sujeito que dá o tom de todo o processo da clínica. De forma geral, a prescrição do Dejours dá conta da pesquisa, mas temos que ajustar temas, horários, quantidade de sessões e, sobretudo, repensar a mobilização subjetiva. Tem sido difícil conseguir este processo em 10 sessões. Penso que para a pesquisa é um número adequado, mas, para transformar a realidade do trabalho, é impossível.

Outro fator de adaptação se refere ao fato de a pesquisa estar sendo desenvolvida em um contexto de pós-graduação visando à elaboração e defesa de uma dissertação ou tese. Quando isso ocorre, em função de várias pressões por prazos, tanto institucionais quanto da banca, o pesquisador deve fazer os ajustes e adaptações necessárias para cumprir a tarefa, conforme declara Selma Lancman.

Selma Lancman comenta: A temporalidade lá na França é muito diferente da nossa realidade aqui no Brasil, pois os prazos das agências de fomento aqui são muito curtos. Outro problema mais complicado ainda é fazer essa pesquisa dentro de um contexto de elaborar uma tese de doutorado. Além do prazo, ainda tem a questão do comitê de ética. É muito difícil conseguir aliar tempo de doutorado, tempo de formação do pesquisador, tempo do comitê de ética e dificuldades de ajustes. . . . é um grande desafio realizar uma intervenção em psicodinâmica do trabalho com todo esse contexto. É um conflito ético que vivenciamos. Na França, se o Dejours não publicar um artigo na revista X, ele continua sendo orientador, aqui não. Se eu não publicar eu perco o direito de orientar. É muito diferente essa realidade. . . em relação às pesquisas como base para as dissertações e teses é difícil imaginarmos os 
alunos fazendo uma clínica, até porque a formação para capacitar o aluno a fazer uma análise clínica é impossível de ser realizada em dois ou quatro anos. Não tem um padrão de orientação.

Quando a pesquisa ou intervenção é realizada fora do âmbito acadêmico, até a forma de validar os resultados, elaborar e encaminhar o relatório é totalmente diferente. Exatamente em função disso é que se privilegia a leitura e publicação de dissertações ou teses em função da impossibilidade de acesso aos relatórios de intervenção, que pertencem exclusivamente ao campo e participantes que demandaram a pesquisa.

Ainda há os pesquisadores que, em nome de uma "adaptação", utilizam as categorias teóricas da Psicodinâmica do Trabalho, mas modificam o método de pesquisa prescrito por Dejours. Em decorrência disso, houve várias discussões, dissidências e cisões entre alguns grupos de pesquisadores, inclusive com o próprio Dejours.

Talvez, o que para alguns pesquisadores é considerado como mais uma adaptação, para outros (inclusive Dejours) é considerado como uma deturpação dos princípios da Psicodinâmica do Trabalho e a mais polêmica tenha sido a elaboração e utilização de escalas psicométricas a partir das categorias teóricas da Psicodinâmica do Trabalho. Esse último fato é fortemente criticado como pode ser observado no relato apresentado:

Laerte Sznelwar: Eu não acho que exista algo que seja um monólito de pedra onde nada de diferente se encaixa. Por outro lado, não dá para aceitar desculpas e aceitar qualquer coisa e chamar de psicodinâmica. Nós estamos mobilizados de um jeito, fazemos pesquisa e nem sempre podemos usar isso em benefício próprio, utilizando tudo isso em forma de artigo. Um dos grandes problemas é deturpar a PDT utilizando métricas. Dejours fica enraivecido com isso, questionários, isso não tem nada a ver com PDT. Seria a mesma coisa que você ir a um consultório de psicanálise e preencher um questionário, não tem nada a ver. Dejours sempre teve uma coerência epistemológica e desenvolveu um método específico para dar conta da proposta. Acho um absurdo uma pesquisa gerar seis, sete papers.

Cabe ressaltar que a Psicodinâmica do Trabalho não propõe medidas de avaliação para seu método. A avaliação pode referir-se à ação dos pesquisadores, mas não sobre a ação no contexto de trabalho feita pelos trabalhadores. Não há proposta de avaliação de mudanças objetivas, visto que o objetivo da clínica do trabalho consiste em promover, nos trabalhadores, a reflexão da sua relação subjetiva com o trabalho.

\section{Críticas e limitações em relação à Psicodinâmica do Trabalho}

Apesar de bem aceita, a abordagem também é alvo de ressalvas, críticas e limitações. Algumas delas se dirigem ao aspecto das relações de poder, quando se coloca a questão de até que ponto é realmente possível haver uma ação de emancipação que resulte em mudança real na organização do trabalho. Outras se ligam à dificuldade de realizar o método prescrito e, ainda, há aquelas que sinalizam que se trata de uma abordagem em construção.

Álvaro Merlo: Acho que ela é uma abordagem teórica. Foi produzida dentro da Ergonomia. Acho que ela chegou ao limite, deu muita contribuição que ficará, mas que é limitada. O Dejours tem uma rede de relações muito complicada. A PDT se expandiu. Ela trabalha com pequenos grupos. A ideia da emancipação é quase utópica, pois o mundo ocidental está comprometido com a lógica do capital. O método da PDT não dá conta de atender a características do objeto. Limitação com trabalho com sindicatos. Às vezes temos que utilizar instrumentos quantitativos para adaptar aos objetos de estudo. 
Selma Lancman: O simples fato de você fazer uma ação em clínica de PDT esbarra numa limitação no que se refere à falta de "empoderamento" do trabalhador para implantar as modificações necessárias. Nesse sentido, vejo como uma limitação. Até que ponto o grupo dos pesquisadores tem a função de incubar, mas depois de um certo ponto o grupo tem que andar com as próprias pernas. E também tem o real do trabalho, quando conseguimos concluir a pesquisa, o campo foi fechado. É frustrante.

Seiji Uchida: Na área privada, essa abordagem não tem espaço porque não há demanda. $\mathrm{O}$ interesse das empresas é de outra ordem. A pressão faz parte do trabalho, em palestras podemos até abordar isso, mas, quando começamos a entrar na crítica, eles recuam, não gostam de abrir espaço para falarmos sobre sofrimento no trabalho. Em palestras e cursos de MBA consigo falar, mas em geral incomoda muito e logo preferem não dar continuidade ao trabalho. Por isso acho que a possibilidade de trabalho ainda é no setor público e aí esbarramos em outras questões culturais. A abertura que encontro ainda é limitada, palestras, mas quando começamos a apresentar a proposta de emancipação e crítica, eles geralmente recuam. Levar questões que permitem aprofundar as contradições organizacionais e levar a um repensar da gestão e isso eles não querem. A PDT, quando inicia, causa um impacto profundo, e isso eles não querem.

Atualmente, há uma verdade incontestável no mundo do trabalho que visa desconstruir, fragmentar e aniquilar o coletivo do trabalho. Quando surge a demanda por uma intervenção, isso pode indicar a possibilidade de uma constituição ou reconstrução de um coletivo laboral. A criação de laços subjetivos dá suporte para a força do grupo e toda sua representação social de resistência e emancipação.

A demanda legitima a intervenção e indica a pertinência da ação da PDT. A reconstrução do coletivo do trabalho ocorre no próprio processo de demanda, ou seja, pedir ajuda já indica a percepção de que o funcionamento atual não atende às necessidades do grupo e que a saída não é individual, passa necessariamente pela mobilização subjetiva do grupo.

Janine Kieling: Sim. As críticas são da difícil aplicação do método stricto sensu e, por isso, a necessidade de adaptação dele. E também acho que a teoria deve evoluir na construção do conhecimento, não estando somente associada ao seu precursor Dejours. Por isso, acredito que temos que adaptar a PDT pensada por ele a nossa realidade, e desenvolver a PDT no Brasil e em outros países. Além disso, a teoria da PDT, como outras teorias, também necessita dialogar com outras vertentes teóricas para dar conta da complexidade de seu objeto que é a saúde mental e o trabalho e da realidade que está sendo aplicada.

É importante comentar que o processo emancipatório dá legitimidade à própria abordagem, ou melhor, à sua existência como campo epistemológico de produção de sentidos e de intervenção. Mesmo quando é limitado, parcial, o processo emancipatório contribui para a ressignificação dos sentidos atribuídos ao trabalho, visando em um primeiro nível à modificação da organização do trabalho e a reorganização interna da mobilização subjetiva em relação ao sofrimento advindo do trabalho.

\section{Discussão}

O objetivo do texto foi descrever a arqueologia da Psicodinâmica do Trabalho no Brasil. Para tal, foram realizadas análise documental e inúmeras entrevistas visando reconstruir esta trajetória desde sua entrada no país, ainda como Psicopatologia do Trabalho, até sua expansão sinalizada pela adoção dessa abordagem teórica e metodológica por vários grupos de pesquisa de instituições de ensino superior, a realização de eventos em âmbito nacional, a grande publicação de trabalhos e a formalização de laboratórios, além da inserção de um grupo de trabalho na ANPEPP. 
Com toda essa expansão e em decorrência de diferenças contextuais e culturais entre a França e o Brasil, surgiram adaptações concernentes a aspectos metodológicos e procedimentais. Ainda não há consenso se em um futuro próximo isso poderá se configurar como a necessidade do desenvolvimento de uma clínica do trabalho brasileira desvinculada da PDT ou se haverá uma melhor compreensão dos princípios e pressupostos da PDT e eventual adaptação ao contexto brasileiro.

Como resultado de sua formação, pode-se afirmar que, para manter uma coerência epistemológica, Dejours estruturou sua abordagem ancorada nos princípios da Ergonomia e da Psicanálise. A essência do fenômeno estudado pela Psicodinâmica do Trabalho é essencialmente da ordem subjetiva; sua epistemologia é antipositivista; a visão da natureza humana é dialética e o método utilizado é necessariamente ideográfico. Com isso, ele a situou necessariamente adotando a teoria do conflito e negando a ideia da integração ou estabilidade. Dito de outra forma, ela não pode ser utilizada visando a "adaptação" do trabalhador, e sim como instrumento de emancipação, sua ação podendo transformar a realidade da organização do trabalho.

Mesmo que a organização do trabalho não absorva todas as sugestões advindas do espaço de discussão coletivo, seguramente a dinâmica laboral poderá ser mais bem compreendida e ressignificada. Como em um processo terapêutico, algumas mudanças dependem de tempo para serem gestadas, implantadas e amadurecidas.

\section{Referências}

Capes. (2017). Portal de periódicos: histórico. Recuperado de https://bit.ly/2SToP1I

Dejours, C. (1992). A loucura do trabalho: estudo de psicopatologia do trabalho (5a ed.). (A. I. Paraguay \& L. L. Ferreira, trad.). São Paulo: Cortez Oboré.

Dejours, C. (1999). Conferências brasileiras: identidade, reconhecimento e transgressão no trabalho. São Paulo: Fundap.

Dejours, C. (2004). Subjetividade, trabalho e ação. Revista Produção, 14 (3), 27-34.

Dejous, C. (2005). O fator humano. (M. I. Betiol \& M. J. Tonelli, trad.). Rio de Janeiro: Ed. FGV.

Dejours, C. (2008). Trabalho, tecnologia e organização: avaliação do trabalho submetida à prova do real. São Paulo: Blucher.

Dejours, C., Abdoucheli, E. \& Jayet, C. (2009). Psicodinâmica do trabalho: contribuições da escola dejouriana à análise da relação prazer, sofrimento e trabalho. (M. I. Betiol, trad.). São Paulo: Atlas.

Dejours C., Dessors D. \& Molinier, P. (1994). Pour comprendre la résistance au changement. Documents du Médecin du Travail, 58, 112-117.

Dejours, C. \& Gernet, I. (2012). Psychopatologie du travail. Paris: Elsevier Masson.

Foucault, M. (1969). Arqueologia do saber. Petrópolis, RJ: Editora Vozes.

Macêdo, K. B. \& Heloani, R. (2017). Introdução e expansão da Psicodinâmica do Trabalho no Brasil: entrevista com Dejours. Psicologia em estudo, 22, 497-502. Recuperado de https://bit.ly/2XiZyDD

Machado, L. S. \& Macêdo K. B. (2016). Análise bibliométrica dos estudos em clínica psicodinâmica do trabalho. Revista Subjetividades, 16, 62-76.

Merlo, A. R. C., Mendes, A. M. \& Moraes, R. D. (2013). O sujeito no trabalho: entre a saúde e a patologia. Curitiba: Juruá. Michaelis. (2018). Dicionário etimológico. Recuperado de https://bit.ly/2XOFGre

Molinier, P. (2013). O trabalho e a psique: uma introdução à Psicodinâmica do Trabalho. (F. Soudant, trad.). Brasília: Paralelo 15. Sznelwar, L. I. (2006). Alain Wisner: o desenvolvimento da ergonomia e do pensamento sobre o trabalhador. Revue Travailler, 15, 226-234.

Endereço para correspondência

katiabarbosamacedo@gmail.com,rheloani@gmail.com
Recebido em: 19/05/2018

Avaliado em: 24/08/2018 Aprovado em: 21/02/2019 